\title{
Varieties of legal systems: towards a new global taxonomy
}

\author{
MATHIAS M. SIEMS* \\ Durham Law School, Durham University, UK
}

\begin{abstract}
Legal scholars, economists and other social scientist often refer to the idea that countries can be classified into a number of 'legal families' or 'legal origins'. Yet, this research is unsatisfactory as regards the actual classifications of the legal systems of the world. It is the aim of this paper to fill this gap and to develop a more robust taxonomy of legal systems. This taxonomy is based on a new dataset of 156 countries that is subsequently analysed with tools of network analysis. Applying cluster optimisation, this paper finds that the world's legal systems can be divided into four clusters. It displays those clusters in a map, akin to the Inglehart-Welzel cultural map. It is suggested that those findings have important implications, not only for our understanding of the legal world, but also for the feasibility of legal transplants and harmonisation.
\end{abstract}

\section{Introduction}

Researchers in many academic disciplines aim to classify countries, for example, trying to identify language families (Lewis et al., 2013), cultural groups (Inglehart and Welzel, 2010), varieties of economic systems (Nielsen, 2011) and forms of capitalism (Hall and Soskice, 2001). Given that there are both differences and similarities between laws across countries, it is also worth exploring whether a similar global classification can be made for legal systems.

It is the aim of this paper to develop such an evidence-based quantitative taxonomy of the legal systems of the world. As it will explain, this approach is different from previous taxonomies of 'legal families' or 'legal origins' as those are not based on a robust method of classifying countries. Thus, this paper aspires to fill this gap in the literature which should be interest for institutional economists, legal scholars, political and other social scientists. In developing this new global taxonomy, the paper aims to strike the right balance between keeping the familiar and presenting new ways of classifying the legal systems of the world in order to make it an attractive tool for other researchers.

The paper is structured as follows: Section 2 outlines the current literature and presents the theoretical framework that underlies the proposed taxonomy. Section 3 discusses the variables of this paper and presents descriptive statistics

*Email: siems@fulbrightmail.org 
for a new dataset of 156 countries. Section 4 shows how tools of network analysis can be used to display a network of the world's legal systems. It also re-examines the alleged relevance of legal-origin classifications. Section 5 calculates, presents and analyses clusters of legal systems, identifying the four clusters 'European Legal Culture', 'Mixed Legal Systems', the 'Rule by Law' and the 'Weak Law in Transition'. Section 6 concludes with reflections on possible further research in this area.

\section{Literature review and theoretical framework}

\section{Previous research on 'legal families' and 'legal origins'}

Legal scholars, economists and other social scientist often refer to the idea that countries can be classified into a number of 'legal families' or 'legal origins'. Legal scholars call those categories 'legal families' and distinguish between common law, civil law, religious legal systems (such as countries of Islamic law) and sometimes add the groups of East Asian law, African law and socialist legal systems (for overviews see e.g., Siems, 2014: 74-80; Pargendler 2012; Husa 2012). However, they do not attempt to classify all countries of the world: rather, in the main comparative law textbooks, the legal family taxonomy serves as a 'didactic device' to outline selected similarities and differences between selected countries (David, 1985: 21; also: Zweigert and Kötz, 1998: 72: 'a rough and ready device'). While some legal scholars refer to the idea of mapping the legal systems of the world (Bavinck and Woodman, 2009; Twining, 1999; Varga, 2010), this is done without producing actual graphic representation.

A notable exception is the Website 'www.juriglobe.ca' of a research group of comparative lawyers at the University of Ottawa. This site divides the world into the categories 'civil law', 'common law', 'Muslim law', 'customary law' and mixtures of those. Yet, the problem is that the precise classifications are left unexplained. For example, the statement that Saudi Arabia is 'Muslim law', Iran a mixture of 'Muslim law' and 'civil law', the UAE a mixture of 'Muslim law' and 'customary law' and Kuwait a mixture of 'Muslim law', 'civil law' and 'customary law', invites the criticism that the researchers would need to have explained precisely what justifies the classifications of these countries.

Since the mid 1990s financial economists have employed the categories of English, French German, Nordic and Socialist legal origins. The context of this research is the question whether and how differences in legal rules may account for differences in financial development. For example, a number of influential studies by Djankov et al. and La Porta et al. scrutinised the effect of country differences as related to investor protection. Most of these studies found that legal rules have indeed a quantifiable effect on financial development. Moreover, the quality of legal rules is said to vary systematically between 'legal origins':

1 http://www.juriglobe.ca/eng/sys-juri/class-poli/droit-musulman.php. 
in particular, it was found that the legal model of 'English legal origin' (i.e., common law) countries is more conducive to financial development than that of other legal origins (e.g., Djankov et al., 2008; La Porta et al., 1998; see also Armour et al., 2009; Siems and Deakin, 2010, for different results).

However, this 'legal origin' taxonomy (summarised in La Porta et al., 2008) is highly problematic. If one traces the source of this taxonomy, there are no substantive explanations why a particular country is considered as belonging to one of these categories - in particular no historical analysis which the 'origin' terminology appears to indicate. Rather, classifying legal systems is simply based on whether, according to a book on foreign law (Reynolds and Flores, 1989), the main codes of these legal systems follow a particular model - and, if there are no such codes, the country is typically seen as part of the English legal origin. It can therefore be shown that about $80 \%$ of these classifications into legal origins are not self-evident (Siems, 2007: 62-70; similar Garoupa and Pargendler, 2014) - while the authors of the legal-origin studies provide no evidence for their classification of individual countries (or why there are only these specific legal origins in the first place).

\section{Rationales for taxonomies of legal systems}

Taxonomies of countries simplify reality, but there are good reasons why such simplification can be a useful endeavour. From a general methodological perspective, they can be related to Karl Popper's view that scientific knowledge grows by way of 'conjectures and refutations' (Popper, 1963). Since taxonomies can never be a perfect representation of the complexities of the real world, they can be seen as, more or less refined, conjectures - and it is then the task of subsequent researchers to critically scrutinise these conjectures and try to develop better ones.

More specifically, the legal taxonomies of countries have a descriptive, analytical and normative dimension. Legal scholars tend to highlight the descriptive value as legal classifications can facilitate the description and understanding of foreign laws. For example, a researcher who analyses legal systems that belong to the same legal family can focus on the remaining differences (Hertel, 2009: 128; Twining, 2000: 152, 178), and an aspiring comparatists who tries to understand the law of a particular foreign country can, given its similarities to his or her own country, then concentrate on the remaining differences between those countries' laws (Bogdan, 1994: 38). Subsequently, as research goes deeper into the specifics of particular countries, it will then, however, be necessary to go beyond the initial taxonomy (Zweigert and Kötz, 1998: 72).

Researchers may also analyse how such legal classifications are related to nonlegal ones. For example, in economic geography, a distinction is made between spatial, institutional, cultural, organisational and relational proximity (Coe et al., 2010: 147-148). Geographers are primarily interested in the spatial aspect and 
lawyers in the institutional one. But if one combines those taxonomies, it may be possible to say whether legal traditions are conditioned by spatial or other non-legal circumstances.

Taxonomies can also have a normative dimension. For example, if it is assumed that belonging to the English legal origin may have possible advantages (see previous section), it could be advisable for countries of other legal origins to shift closer to the model of the common law. An alternative normative position is that what matters are the familiarity with and the adaptation of the transplanted legal system (Berkowitz et al., 2003a and 2003b; similar for policy transfers, Lalenis et al., 2002). Here too then one could argue that legal taxonomies provide useful normative information as they can help to illuminate the degree of familiarity between different legal systems.

\section{Challenges and possible criteria}

A modern critique of legal families is that, in today's world, law has become predominantly international, transnational or even global, so that looking at the way laws differ between countries is seen as less important (see Husa, 2004; Reimann, 2001). But, it would also go too far to claim that all country differences have disappeared. Moreover, a taxonomy - such as the one proposed in this paper - can precisely be a means to establish how far we can still classify legal systems into plausible groups of countries today.

Further, it may be objected that there cannot be just one classification of legal systems. There is bound to be a degree of subjectivity since, to classify countries, means making a decision about some common aspects that matter, while disregarding others (Peters and Schwenke, 2000: 826). A further complication is that most countries can be called 'vertically divided legal systems' since different areas of law may have been influenced by different foreign legal models (Siems, 2014: 89-92); thus, there may be various classifications, depending on the area of law that is the main focus of the researcher in question.

However, comparative lawyers also take the view that it is possible to approach comparative law at the macro level (see, e.g., Zweigert and Kötz, 1998: 4-5), namely that it is legitimate to compare legal systems at the country level as a whole since they consist of more than their individual components. Correspondingly, the comparative-law literature tends to agree on the criteria that form the bases of classifications of legal systems. The main idea is to use criteria that are good indicators for the entire legal system - as opposed to possible idiosyncrasies of a particular area of law - and that are relatively 'permanent' and 'determinant', not merely 'incidental' or 'fungible' (Constantinesco, 1983: 241; Luts, 2011: 41). Common features of the legal family taxonomies are therefore the level of codification, differences in legal style and mentality, the effectiveness of the law and the law's underlying rationales (Husa, 2012: 492-493; also Vanderlinden, 1995: 328, identifying 14 criteria used in the comparative-law literature). 
As a result, any choice of variables should aim to capture such determinant legal features. In this respect, the term 'legal' is to be understood in a wide sense, encompassing both the 'law in the books' and the 'law in action' (similar, for measuring institutions, Voigt, 2013). While it is clear that measuring the 'law in action' can be difficult, this approach was seen as preferable to a mere 'law in books' approach since the latter would disregard that the positive law may be underenforced in some countries.

It may also be contemplated to include non-legal variables related to history, culture or geography as far as those may be regarded as good proxies for legal differences. For example, history can come into play since 'legal traditions' (e.g., Derrett, 1968; Glenn, 2014) may be decisive for the shape of the law today, such as the influence of Roman law on civil law (but also common law) countries and the relevance of colonial origins for many countries in the developing world (see Klerman et al., 2011 and Siems 2007: 76-80, comparing legal and colonial origins). Cultural and spatial proximity may be relevant as factors stimulating the diffusion of legal ideas across countries. However, it is difficult to say $a$ priori how far such non-legal factors reflect legal differences. Thus, in the choice of variables, preference has been given to variables that have a direct legal dimension and measure the current law.

In order to go beyond the anecdotal classifications of the current legal literature, another aim was to include most legal systems of the world. The availability of legal datasets means that two limitations have to be acknowledged. First, the available datasets do not cover smaller jurisdictions in Oceania and the Caribbean, as well as countries which do not take part in international surveys such as North Korea. Second, most of these datasets do not consider that there may be differences within one country. For example, while it is the case that the laws of Quebec, Louisiana and Scotland are different from that of other parts of Canada, the US and the UK, legal datasets only provide a single number for each of those countries (the same applies to other sub-national variations of the law). As a result, the dataset that will be described in the following covers 156 countries (with the names of those countries to be found in Table 7, below).

\section{Variables and descriptive statistics}

\section{Variables of this study}

This study is based on 15 variables. The choice of these variables follows the considerations outlined in the previous section. More specifically, the variables can be divided into three main categories with five variables each (overview in Table 1, below).

The first five variables aim to capture commonalities between groups of countries. Variable (1) considers whether countries consider themselves as belonging to the Latin Notariat (UINL), an organisation that aims to coordinate 
the work of notaries based on a 'civilian' notary system. Variable (2) on 'Islam as state religion' indicates whether Sharia law is likely to play at least some role in those countries. Variable (3) considers that the legal systems of the countries of the European Union (EU) - and those of Iceland, Liechtenstein and Norway, as they belong to the European Economic Area (EEA) - are based to a large extent on EU law. This goes beyond the rules of other regional organisations. It also goes beyond a mere following of some EU laws by other countries (e.g., by Switzerland) since, in the EU, those common rules can also be enforced by the courts of the EU and the EEA.

To further consider the transnational and international dimension of today's laws, variable (4) codes the participation of countries in international initiatives in matters of private and commercial law, namely, the Hague Conference on Private International Law, Unidroit and the CISG, with each of those accounting for $1 / 3$ of the score. Variable (5) considers the increasing judicialisation of international law. It codes the participation of countries in the International Court of Justice, the International Criminal Court and the WTO with its dispute settlement mechanism, again with each of those elements accounting for $1 / 3$ of the score.

The next five variables code attributes related to the general legal infrastructure of countries. Variable (6) addresses whether they adhere to the 'rule of law' based on the comprehensive dataset developed by Kaufmann et al. (2010). It was also contemplated to include data on corruption; yet, the corresponding index by Transparency International is highly correlated with the rule of law index (0.95). It also needs to be acknowledged that such aggregated indicators have been subject to criticism (e.g., Kurtz and Schrank, 2007; Voigt, 2013). In the present case, it is suggested, however, that it is helpful to include the 'rule of law' indicator since it can fill gaps left by the choice of some of the narrower indicators chosen for the purpose of this paper.

Variable (7) on judicial independence may be seen as related. However, in order to provide a good mix between variables about the positive law and the law in practice, this variable is based on a dataset that codes the constitutional provisions decisive for judicial independence. Variable (8) considers another constitutional issue, namely whether countries have a separate constitutional court. This variable was included because the existence or lack of a constitutional court may shape the general structure of highest courts in a country. It also reflects whether countries follow the position, originally developed by Hans Kelsen, that a separate constitutional court is necessary because ordinary courts only have the task of applying, but not evaluating, parliamentary laws (see Ferreres Comella, 2011). A related variable may have considered the reliance on a career judiciary; yet, world-wide data on this topic are not available (see Garoupa and Ginsburg, 2011).

The subsequent two variables address legislation and law-making. Variable (9) codes whether countries have a Civil Code. The existence of such a code is 
important for the mentality of a legal system since such a codification aims to be of a systematic and comprehensive nature. In general, it was straight-forward to code this variable. As the focus of this paper is on entire countries (see above), Codes that are only in place in a minor part of federal countries were disregarded (relevant for the US, Canada and Cameroon). For the six countries that only have a Code of Obligations this variable was coded as 0.5. Variable (10) considers democratic structures since in non-democratic countries 'law' and 'politics' tend to be less clearly separated than in democratic ones. This relevance of the 'rule of political law' is also accepted in the taxonomy by Mattei (1997).

The final five variables address specific areas of law - while, here too, the aim was to choose variables that relate to general themes and attitudes of legal systems. The extent of civil liberties violations, considered in variable (11), reflects the general relationship between the state and its citizens. Variable (12) on economic freedom aims to capture the general approach of countries towards less or more procedural formalities in business law. Variable (13) on labour freedom has the purpose to identify countries with a strong social orientation of the law, say, coordinated market economies, as opposed to purely liberal ones (see Hall and Soskice, 2001). This legal dataset was preferred to more economic or political proxies, such as data on the tax revenue, size of the government, left/right orientation or the Gini coefficient. The abolishment of the death penalty of variable (14) intends to identify the 'harshness' of a country's criminal law. Finally, variable (15) codes the extent to which abortion is permitted in a particular jurisdiction. This variable aims to consider to what extent the law of a country tends to be more socially conservative or liberal.

\section{Descriptive statistics}

Table 1 summarises the 15 variables used in this paper, together with the sources, means, medians and standard deviations for 156 countries. In order to have a uniform measure, the variables were scaled from 0 to 1 , if necessary.

Table 2 highlights the variable pairs with the highest correlation coefficients ( $|0.50|$ or higher). It can be seen that the relationships between EU/EEA membership, participation in international commercial law, rule of law, democracy, civil liberties and business freedom tend to be among those correlations. It is also interesting to consider some of the other correlations: for example, countries where Islam is the state religion tend to have retained the death penalty (0.403); and countries with the death penalty also tend to infringe other civil liberties (0.432).

The final line of Table 2 indicates the average absolute correlation of each of the 15 with the other 14 variables. It can be seen that none of the variables dominates the dataset. This is deliberate in order to avoid the risk that adding or dropping one of the variables would lead to a fundamentally different result. 
Table 1. List of variables and descriptive statistics $(n=156)^{2}$

\begin{tabular}{|c|c|c|c|c|}
\hline Variables & Sources & Mean & Median & Std. deviation \\
\hline (1) Countries of Latin notariat & $\begin{array}{l}\text { International union of } \\
\text { notaries }\end{array}$ & 0.474 & 0.000 & 0.499 \\
\hline (2) Islam state religion & $\begin{array}{l}\text { CIA world factbook } \\
\text { (and other sources) }\end{array}$ & 0.115 & 0.000 & 0.319 \\
\hline (3) EU/EEA countries & European union & 0.192 & 0.000 & 0.394 \\
\hline $\begin{array}{l}\text { (4) Participation in international } \\
\text { commercial law }\end{array}$ & Respective websites & 0.455 & 0.333 & 0.403 \\
\hline $\begin{array}{l}\text { (5) Participation in international } \\
\text { courts }\end{array}$ & Respective websites & 0.643 & 0.667 & 0.321 \\
\hline (6) Rule of law & $\begin{array}{l}\text { World bank governance } \\
\text { indicators }\end{array}$ & 0.450 & 0.377 & 0.265 \\
\hline $\begin{array}{l}\text { (7) Judicial independence } \\
\text { (according to constitution) }\end{array}$ & $\begin{array}{l}\text { Comparative } \\
\text { constitutions project }\end{array}$ & 0.427 & 0.333 & 0.244 \\
\hline (8) Constitutional court & Concourts.net & 0.372 & 0.000 & 0.483 \\
\hline (9) Civil Code & Foreign law guide & 0.686 & 1 & 0.454 \\
\hline (10) Democracy index & $\begin{array}{l}\text { Economist intelligence } \\
\text { unit }\end{array}$ & 0.495 & 0.525 & 0.254 \\
\hline (11) Civil liberties infringed & Freedom house & 0.397 & 0.333 & 0.300 \\
\hline (12) Business freedom & Heritage foundation & 0.584 & 0.578 & 0.204 \\
\hline (13) Labour freedom & Heritage foundation & 0.513 & 0.508 & 0.210 \\
\hline (14) Death penalty not abolished & Amnesty international & 0.269 & 0.000 & 0.444 \\
\hline (15) Abortion permitted & $\begin{array}{l}\text { World population } \\
\text { policies database (UN) }\end{array}$ & 0.598 & 0.571 & 0.354 \\
\hline
\end{tabular}

\section{Matrix, network presentation and analysis}

\section{Method and matrix of differences}

In this paper, network analysis is seen as a method, not a particular substantive concept (for this distinction, see Mische, 2011). Network analysis requires relational data. For example, the research on 'world systems' uses data such as trade flows in order to establish the power relationship between rich and poor countries (Lloyd et al., 2009, for an overview).

The data of Table 1 describes attributes of countries. However, this data can also be presented as a relational dataset. For example, the variable about EU/EEA membership is akin to a variable about membership in the same intergovernmental organisation used in the world systems literature (Snyder

2 Internet references for sources (data for 2013 unless indicated otherwise): (1) www.uinl.org; (2) www.cia.gov/library/publications/the-world-factbook/; (3) to (5) websites of organisations; (6) www. govindicators.org; (7) http://comparativeconstitutionsproject.org/ccp-rankings/ (most recent years); (8) www.concourts.net (own research for gaps); (9) http://referenceworks.brillonline.com/browse/ foreign-law-guide; (10) www.eiu.com (2012 data); (11) www.freedomhouse.org; (12) and (13) www. heritage.org/index/explore (2014 data); (14) www.amnesty.org; (15) http://esa.un.org/PopPolicy/ wpp_datasets.aspx. 
Table 2. Correlations between the variables of Table 1

\begin{tabular}{|c|c|c|c|c|c|c|c|c|c|c|c|c|c|c|c|}
\hline & & (2) & (3) & (4) & $(5)$ & (6) & (7) & (8) & (9) & (10) & (11) & (12) & (13) & (14) & $(15)$ \\
\hline (1) & 1 & -0.182 & 0.253 & 0.360 & 0.337 & 0.081 & -0.024 & 0.305 & 0.545 & 0.221 & -0.317 & 0.029 & -0.202 & -0.403 & 0.110 \\
\hline$\overline{(2)}$ & -0.182 & 1 & -0.176 & -0.175 & -0.328 & -0.055 & -0.180 & -0.153 & 0.029 & -0.302 & 0.357 & 0.033 & 0.039 & 0.414 & -0.229 \\
\hline (3) & 0.253 & -0.176 & 1 & 0.592 & 0.442 & 0.629 & -0.121 & 0.197 & 0.033 & 0.549 & -0.591 & 0.450 & -0.019 & -0.296 & 0.396 \\
\hline (4) & 0.360 & -0.175 & 0.592 & 1 & 0.38 & 0.578 & -0.004 & 0.239 & 0.051 & 0.629 & -0.611 & 0.515 & 0.094 & -0.267 & 0.467 \\
\hline (5) & 0.337 & -0.328 & 0.442 & 0.38 & 1 & 0.39 & 0.069 & -0.026 & -0.065 & 0.548 & -0.595 & 0.164 & -0.035 & -0.346 & 0.337 \\
\hline (6) & 0.081 & -0.055 & 0.629 & 0.578 & 0.39 & 1 & -0.117 & 0.004 & -0.194 & 0.771 & -0.737 & 0.737 & 0.339 & -0.159 & 0.396 \\
\hline (8) & 0.305 & -0.153 & 0.197 & 0.239 & -0.026 & 0.004 & -0.016 & 1 & 0.372 & 0.008 & -0.076 & 0.137 & -0.004 & -0.228 & 0.242 \\
\hline (9) & 0.545 & 0.029 & 0.033 & 0.051 & -0.065 & -0.194 & -0.196 & 0.372 & 1 & -0.178 & 0.109 & -0.156 & -0.236 & -0.121 & 0.545 \\
\hline (10) & 0.221 & -0.302 & 0.549 & 0.629 & 0.548 & 0.771 & 0.032 & 0.008 & -0.178 & 1 & -0.926 & 0.600 & 0.139 & -0.331 & 0.344 \\
\hline (11) & -0.317 & 0.357 & -0.591 & -0.611 & -0.595 & -0.737 & -0.038 & -0.076 & 0.109 & -0.926 & 1 & -0.544 & -0.096 & 0.432 & -0.367 \\
\hline (12) & 0.029 & 0.033 & 0.450 & 0.515 & 0.164 & 0.737 & -0.002 & 0.137 & -0.156 & 0.600 & -0.544 & 1 & 0.357 & -0.128 & 0.514 \\
\hline (13) & -0.202 & 0.039 & -0.019 & 0.094 & -0.035 & 0.339 & -0.004 & -0.004 & -0.236 & 0.139 & -0.096 & 0.357 & 1 & 0.137 & 0.247 \\
\hline (14) & -0.403 & 0.414 & -0.296 & -0.267 & -0.346 & -0.159 & -0.086 & -0.228 & -0.121 & -0.331 & 0.432 & -0.128 & 0.137 & 1 & -0.191 \\
\hline (15) & 0.110 & -0.229 & 0.396 & 0.467 & 0.337 & 0.396 & 0.061 & 0.242 & 0.545 & 0.344 & -0.367 & 0.514 & 0.247 & -0.191 & 1 \\
\hline
\end{tabular}


Table 3. Matrix of legal differences of each country pair (extract)

\begin{tabular}{lllllll}
\hline \hline & Albania & Algeria & Angola & Argentina & Armenia &.. \\
\hline Albania & & & & & & $\cdots$ \\
Algeria & 0.358 & & & & & $\cdots$ \\
Angola & 0.311 & 0.286 & & & & $\cdots$ \\
Argentina & 0.182 & 0.307 & 0.347 & & & $\cdots$ \\
Armenia & 0.111 & 0.311 & 0.264 & 0.293 & & $\ldots$ \\
Australia & 0.397 & 0.578 & 0.531 & 0.362 & 0.423 & $\cdots$ \\
$\ldots$ & $\cdots$ & $\cdots$ & $\cdots$ & $\cdots$ & $\cdots$ & $\cdots$ \\
\hline \hline
\end{tabular}

and Kick, 1979; Kick et al., 2011). It is also possible to transform the other variables into variables showing the difference between each country pair. Such an approach of turning attributes into relations is described in network analysis books (e.g., Hanneman and Riddle, 2005: ch. 6; Knoke and Yang, 2008: 7) and is frequently used in political science and international relations (e.g., Sommerer et al., 2008; also Siems, 2010, for an application to legal data).

To elaborate, based on the variables of Table 1, it was calculated how different each variable in the law of a country is to the same variable in the law of the other 155 countries. Subsequently, the absolute values of these differences were added together and divided by 15 . This latter procedure of creating a single index from multiple relations is also accepted in network analysis (e.g., Hanneman and Riddle, 2005: ch. 16; for examples from the world systems research see Kick et al., 2011; Lloyd et al., 2009).

The resulting adjacency matrix shows the average difference between each country pair. For example, in Table 3 it can be seen that Albania is closer to Armenia (average difference of 0.111) than to Algeria, Angola, Argentina and Australia (average differences of $0.182,0311,0.358$ and 0.397 ).

The full matrix contains information about $1+2+3 \ldots 156=12,090$ country pairs. Figure 1 shows the distribution of this data. The mean difference between the country pairs is 0.34672 . Four of the country pairs only have a difference of less than 0.025: Italy-Spain, Norway-Sweden, Finland-Sweden and HungaryRomania. It is suggested that these pairs illustrate the plausibility of the choice of variables as these most similar pairs are geographically close countries with similar legal, social and political structures.

\section{Presentation of matrix as network}

The next step is to present the difference matrix graphically. For this purpose, the information about each of the pairs was entered into a network analysis programme (UCINET) enabling the researcher to represent only those 'ties' (i.e., relationships between countries) that are below a particular threshold (in other words, to dichotomise the network data). 
Figure 1. (Colour online) Distribution of differences of country pairs.

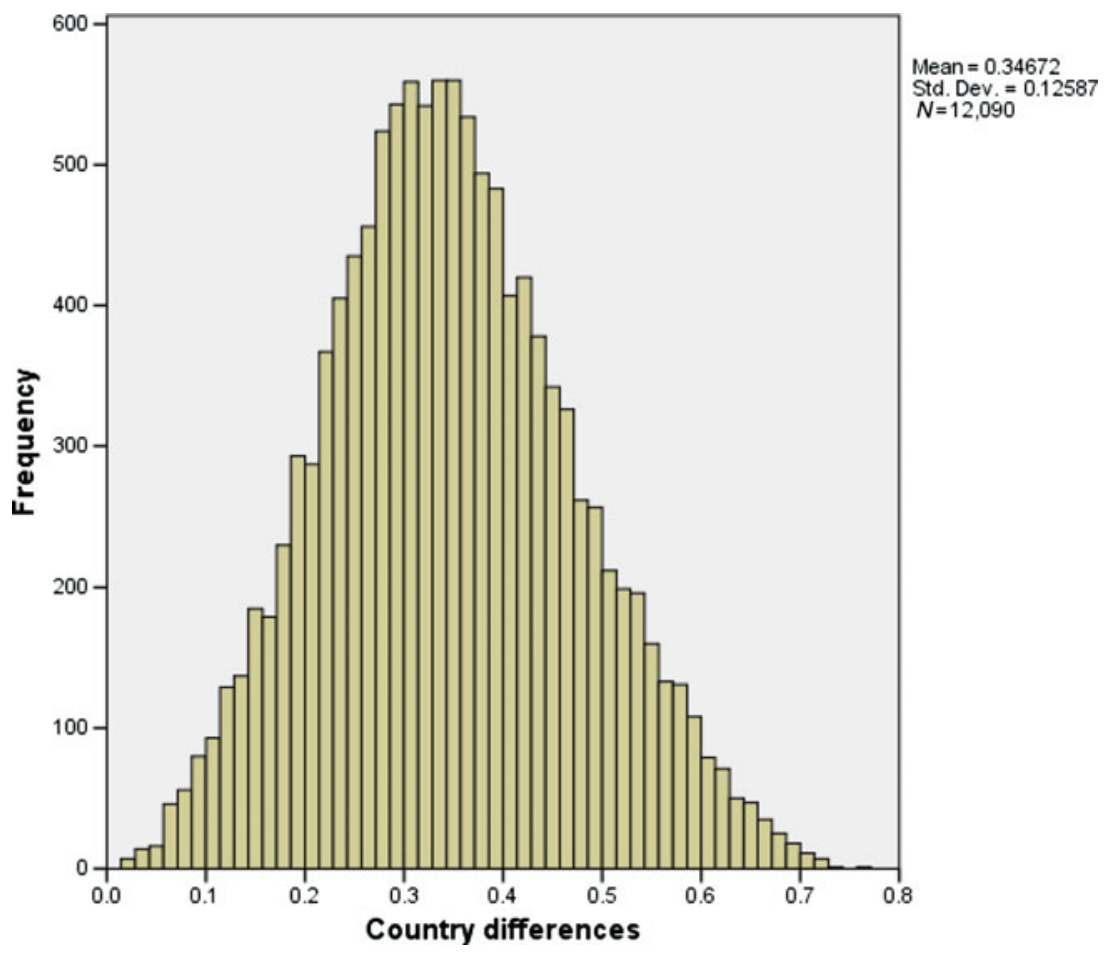

This was done for the value 0.15 which leads to the display of the closest 675 (ca. $5.6 \%$ ) of the country pairs. Subsequently, the network analysis programme was instructed to shift the position of countries according to the strength of their relationships based on the technique of 'spring embedding', i.e., countries whose laws are relatively similar are moved closer together.

Starting at the top of the graph of Figure 2, there are some common law countries with the ones on the right densely connected to the Nordic countries. Clockwise, those countries are then loosely connected to a group of countries which are predominantly from continental Europe. Towards the bottom of the graph, those countries are connected to, mainly, transition economies from eastern Europe and central Asia, and towards the centre there are some connections to developing countries in Africa and Latin America.

On the left centre and bottom of the graph, we find many Muslim countries from the Middle East and North Africa, more or less well connected. Further to the top, there is then a connection between these countries and Bangladesh, Malaysia and Pakistan. Those latter countries are connected to a dense group of common law countries from Africa and Asia, with Israel providing a link back to the European countries. Finally, on the top left it can be seen that three countries 
Figure 2. (Colour online) Network of world's legal systems.

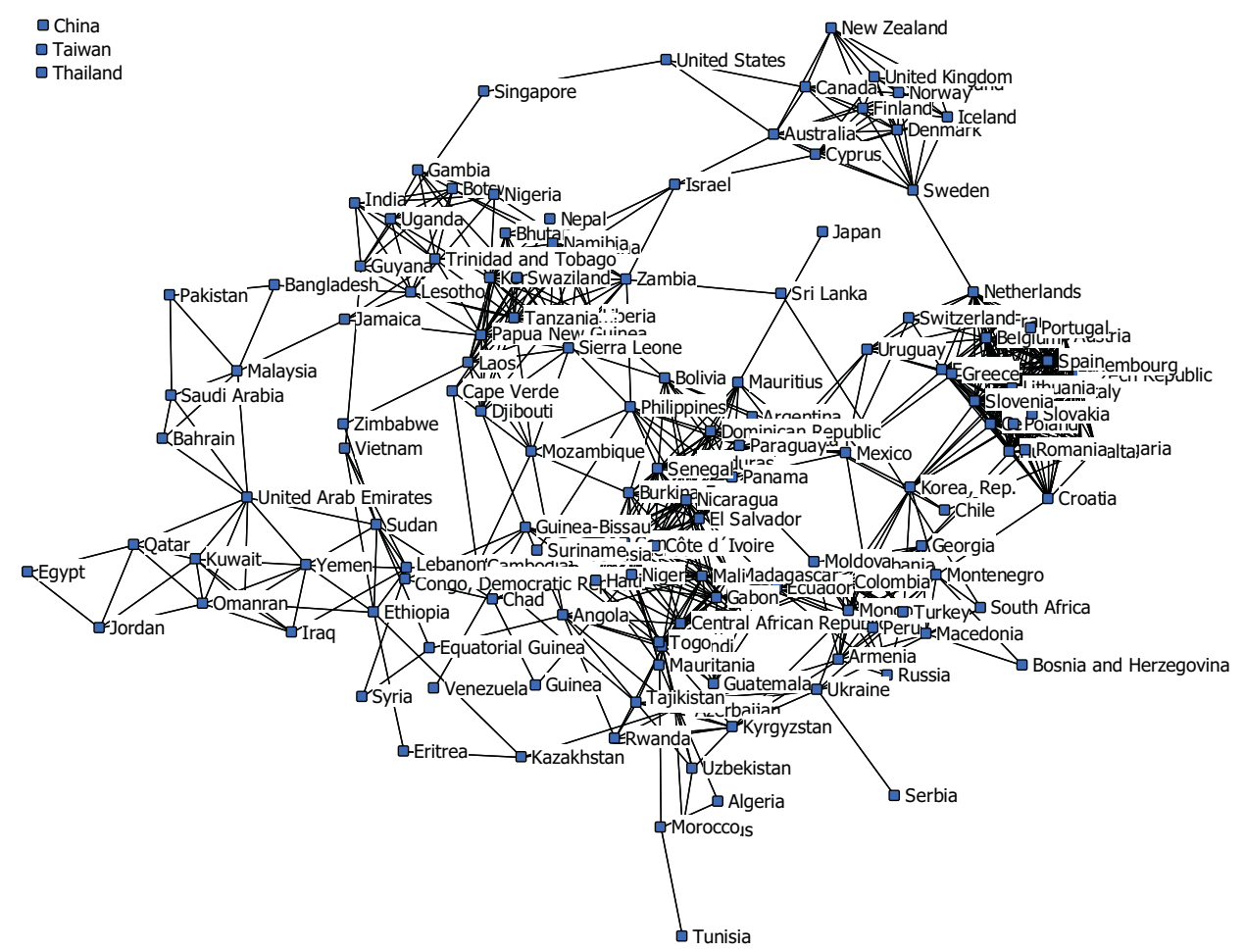

(China, Taiwan and Thailand) are 'isolates', meaning that with a 0.15 threshold they are not connected to any of the other countries.

The limitation of Figure 2 is that it is based on the choice of this cut-off point and that it does not make use of the full information of the valued matrix. Fortunately, network analysis programmes also enable an evaluation of this full information. The following analysis is therefore based on tools that do not rely on a particular cut-off point.

\section{Examining the relevance of legal origins}

According to research by financial economists, there are profound differences between English, French, German, Nordic and Socialist legal origin countries, explaining differences in financial development (see 2, above). To start with, this means that one would expect that the 'origin countries' England (i.e., here the UK, see above). France and Germany are somewhere at the centre of the network (or, at least, form a well-connected hub within a group of countries). This question may invite tools such as calculation of degree or betweenness centrality or a coreperiphery analysis, but those tools work best for binary data (e.g., Hanneman and Riddle, 2005: ch. 10). Thus, in the present case of a valued dataset, it is preferable to calculate and then to rank the average difference of each country 
Table 4. Rank of countries according to average difference (selection)

\begin{tabular}{lll}
\hline \hline 1. Burkina Faso (0.279) & $\ldots$ & 152. Yemen $(0.420)$ \\
2. Philippines $(0.285)$ & 97. France $(0.359) \ldots$ & 153. Saudi Arabia $(0.423)$ \\
3. Panama $(0.286)$ & 133. United Kingdom $(0.392)$ & 154. Bahrain $(0.423)$ \\
4. Nicaragua $(0.288)$ & 136. Germany $(0.396) \ldots$ & 155. Norway $(0.433)$ \\
5. Mozambique $(0.289)$ & $\ldots$ & 156. Denmark $(0.437)$ \\
\hline \hline
\end{tabular}

Table 5. Density of legal origins in network

\begin{tabular}{lrll}
\hline \hline Countries & $n$ & $\begin{array}{l}\text { Average density (and } \\
\text { standard deviation) }\end{array}$ & $\begin{array}{l}\text { Comparison of density with density of all } \\
\text { countries: }{ }^{3} z \text {-score with significance level }\end{array}$ \\
\hline English legal origin & 41 & $0.265(0.095)$ & $-6.8170^{* * *}$ \\
French legal origin & 72 & $0.300(0.120)$ & $-3.8537^{* * *}$ \\
Socialist legal origin & 32 & $0.227(0.123)$ & $-4.5970^{* * *}$ \\
German legal origin & 6 & $0.246(0.121)$ & $-1.5754^{*}$ \\
Nordic legal origin & 5 & $0.049(0.026)$ & $-20.9804^{* * *}$ \\
All countries & 156 & $0.347(0.126)$ & Note: ${ }^{* * *} 1 \%, * * 5 \%, * \%$ significance levels \\
\hline \hline
\end{tabular}

from the other 155 countries. Table 4 shows the five most 'mainstream' and most 'eccentric' countries, as well as the position of France, Germany and the UK.

It can be seen that the three 'origin countries' are relatively 'eccentric', thus, casting doubts on the basis of the legal origin view. By contrast, many of the 'most mainstream' countries are countries in transition, possibly because those have legal institutions which have been shaped by various sources of influence and which provide an average level of protection, for example, as regards civil liberties and rule of law.

The alleged relevance of legal origins can also be examined at the aggregate level of the 'legal origins', based on the categories used in the La Porta et al. studies. ${ }^{4}$ For this purpose, Table 5 reports the 'density' of the five legal origins which, for a valued network, refers to 'the total of all values divided by the number of possible ties' whereby 'the density gives the average value.'

The results of Table 5 show that the average density of each of the legal origins is lower than the density of all countries. In particular, there is strong evidence that the English, Socialist and Nordic legal origins are denser than the average, with only weak evidence for the German legal origin. The observation

3 The UCINET function is Networks > Compare densities > Against theoretical parameter. This uses a bootstrap method, see Hanneman and Riddle 2005: ch. 18. The significance level is based on the 'proportion of differences as small as observed'.

4 The subsequent categories are based on La Porta et al., dataset for 'Government Ownership of Banks' (2002), available at http://faculty.tuck.dartmouth.edu/images/uploads/faculty/ rafael-laporta/Govt_Ownership_Banks.xls.

5 Definition at http://www.analytictech.com/ucinet/help/g75bzo.htm. 
Table 6. Measures of cluster adequacy for legal origins

\begin{tabular}{|c|c|c|}
\hline Indicator & Definitions ${ }^{6}$ & Value \\
\hline Eta & $\begin{array}{l}\text { 'Eta is the correlation between the data matrix and an ideal structure matrix } \\
\text { in which } x(i, j)=1 \text { if } I \text { and } j \text { are in the same cluster and } 0 \text { otherwise' }\end{array}$ & -0.327 \\
\hline$Q$ & $\begin{array}{l}\text { 'Newman and Girvan's modularity } Q \text { is the fraction of edges that fall within } \\
\text { the partition minus the expected such fraction if the edges were distributed } \\
\text { at random, } Q \text { has a maximum value of } 1-1 / m \text { where } m \text { is the number of } \\
\text { clusters. ( ...)' }\end{array}$ & -0.052 \\
\hline Q-prime & 'Q-prime is a normalised version of this'. & -0.065 \\
\hline$E-I$ & $\begin{array}{l}\text { 'Krackhardt and Stern's E-I index is the number of external ties minus the } \\
\text { number of internal ties divided by the total number of ties'. }\end{array}$ & 0.466 \\
\hline
\end{tabular}

that the Nordic countries are particularly close does not come as a surprise, as they are all developed countries with similar legal institutions. It is also plausible that English legal origin countries are denser than the countries of French and German legal origin since the former countries, but not most of the latter ones, share a common legal language and culture (Siems, 2008: 142-3). The strong significance of socialist legal origin may be less expected, given that it may be seen as one of today's 'weakening' legal traditions (cf. Husa, 2004: 31, distinguishing 'strengthening' and 'weakening' legal families).

However, the mere fact that the legal origins are not random does not mean that the dataset supports the legal-origin classification. Cluster adequacy indicators are a formal way to measure the fit of classifications. These indicators range from -1 to 1 , similar to a correlation coefficient. For network data which show dissimilarities (as here), one can expect that the first three indicators are negative and that the final one is positive: this is the case in Table 6; however, all four indicators are closer to 0 than to -1 or 1 . This shows the limitations of the legal-origin taxonomy, and the need for a new classification of the legal systems of the world.

\section{Clusters of legal systems}

\section{Identifying community structures}

Network analysis provides various tools to identify community structures (see, e.g., Ferligoj et al., 2011; Knoke and Yang, 2008: 77-91; Hanneman and Riddle, 2005: chs. 11 and 13). Some of those tools rely on binary data, but for a valued network it is preferable to use tools that consider the full information of the dataset.

In the world-systems literature, a common approach to identify groups in a valued network has been a method called CONCOR which stands for

6 See http://www.analytictech.com/ucinet/help/hs3035.htm. 
'convergence of iterated correlations' (the seminal paper was Snyder and Kick (1979); see also Kick et al., 2011). However, today, CONCOR is technically outdated, with researchers preferring methods of 'Tabu search' (see, e.g., Hanneman and Riddle, 2005: ch. 13; Lloyd et al., 2009: 59).

One such method is to calculate 'optimisation clusters'. This refers to a formal method that 'optimises a cost function which measures the total distance or similarity within classes for a proximity matrix' ${ }^{7}$ The user has to determine in advance how many clusters shall be created. Subsequently, she can compare the reported $r$-square in order to establish the best division for the dataset in question. This has been the approach of the following section.

\section{Clusters and maps of legal systems}

Table 7 reports the result for a division four clusters given that this provides the best fit for the current dataset, using density (defined as 'the average value within clusters for similarity and the sum for distance data') as the fit criterion.

The four clusters of Table 7 have been given names that will be explained in the following. The Table also reports the density of the clusters. It can be seen that the differences within the clusters (in bold) are always lower than the differences to the other clusters - which is precisely the aim of cluster optimisation.

Figure 3 displays the clusters in a world map. It shows that, to some extent, geography is correlated with the clusters since the countries of Europe and South America tend to belong to the same respective clusters. There is also some geographical clustering in Asia and Africa, while it does not confirm a common group of African legal systems - sometimes discussed in the literature (Menski, 2006; Siems, 2014: 83-84).

It may be seen as problematic that the clusters pigeon-hole very diverse countries together. Specialised programmes can identify overlapping groups of nodes in networks, ${ }^{8}$ but in the present case it is also revealing to calculate which three cluster members are the most and least typical ones, see Table $7 .{ }^{9}$ With respect to most typical countries, it can be observed that in the first cluster are continental European countries, in the second cluster are countries that are at the periphery of the common law and in the third cluster are countries that have been politically unstable in recent history.

In terms of the least typical countries of the respective clusters, a plausible interpretation is that those countries are untypical because they are also close to one of the other clusters. For example, with respect to the first two clusters, Japan could have also been in the mixed second cluster, while New Zealand

7 Definition at http://www.analytictech.com/ucinet/help/2cvtid.htm. By contrast, Graff (2008) uses the La Porta $e t$ al. data for hierarchical clustering presented in a dendrogram. Yet, for 156 countries (as here) such a dendrogram would not be informative.

8 See, e.g., CFinder, available at http://cfinder.org/.

9 In the present case of a valued network, this approach is preferable to measures of centrality developed in network analysis. See 4, above. 
Table 7. Clusters of legal systems

Group assignments (most typical countries of cluster in bold; least typical ones in italics)

\begin{tabular}{cc} 
(1) European legal & Australia, Austria, Belgium, Bulgaria, Canada, Chile, Croatia, Cyprus, Czech \\
culture (38 & Republic, Denmark, Estonia, Finland, France, Germany, Greece, Hungary, \\
countries) & Iceland, Ireland, Italy, Japan, Korea, Rep., Latvia, Lithuania, Luxembourg, \\
& Malta, Netherlands, Norway, Poland, Portugal, Romania, Serbia, Slovakia, \\
& Slovenia, Spain, Sweden, Switzerland, United Kingdom, Uruguay \\
(2) Mixed legal & Bahrain, Bangladesh, Bhutan, Botswana, Cape Verde, Djibouti, Gambia, Ghana, \\
systems (38 & Guyana, India, Israel, Jamaica, Kenya, Laos, Lesotho, Liberia, Malawi, \\
countries) & Malaysia, Namibia, Nepal, New Zealand, Nigeria, Pakistan, Papua New \\
& Guinea, Philippines, Saudi Arabia, Sierra Leone, Singapore, South Africa, Sri \\
& Lanka, Swaziland, Taiwan, Tanzania, Trinidad and Tobago, Uganda, United \\
(3) Rule by law (37 & States, Zambia, Zimbabwe \\
countries) & Algeria, Angola, Azerbaijan, Belarus, Burundi, Cambodia, Chad, China, Congo, \\
& Democratic Republic, Egypt, Equatorial Guinea, Eritrea, Ethiopia, Guinea, \\
& Guinea-Bissau, Iran, Iraq, Jordan, Kazakhstan, Kuwait, Kyrgyzstan, Lebanon, \\
& Mauritania, Mozambique, Oman, Qatar, Rwanda, Sudan, Syria, Tajikistan, \\
(4) Weak law in & Thailand, Ukraine, United Arab Emirates, Uzbekistan, Venezuela, Vietnam, \\
transition (43 & Yemen \\
countries) & Albania, Argentina, Armenia, Benin, Bolivia, Bosnia and Herzegovina, Brazil, \\
& Burkina Faso, Cameroon, Central African Republic, Colombia, Congo, \\
& Republic, Costa Rica, Côte d'Ivoire, Dominican Republic, Ecuador, El \\
& Salvador, Gabon, Georgia, Guatemala, Haiti, Honduras, Indonesia, \\
& Macedonia, Madagascar, Mali, Mauritius, Mexico, Moldova, Mongolia, \\
& Montenegro, Morocco, Nicaragua, Niger, Panama, Paraguay, Peru, Russia, \\
& Senegal, Suriname, Togo, Tunisia, Turkey \\
\hline
\end{tabular}

Density table

\begin{tabular}{lllllc} 
& 1 & 2 & 3 & 4 & \\
\hline 1 & 0.215 & 0.448 & 0.496 & 0.350 & \\
2 & 0.448 & 0.231 & 0.338 & 0.361 & r-square $=0.291$ \\
3 & 0.496 & 0.338 & 0.263 & 0.335 & fit: 1356.315 \\
4 & 0.350 & 0.361 & 0.335 & 0.210 & \\
\hline \hline
\end{tabular}

may have joined Australia in the first cluster. Bahrain from the second cluster could have belonged to the third cluster, and, with respect to the fourth cluster, Macedonia and Bosnia and Herzegovina may be close to the European cluster. This intuition can be corroborated with a visual presentation of the clusters, akin to the cultural maps developed by Inglehart and Welzel (2010).

Figure 4 is based on a 'metric multidimensional scaling' (MDS) of the legal systems. This is defined as 'given a matrix of proximities (similarities or dissimilarities) among a set of items, the programme finds a set of points in $k$-dimensional space such that the Euclidean distances among these points corresponds as closely as possible to the input proximities'. ${ }^{10}$ The nodes were

10 See http://www.analytictech.com/ucinet/help/12ugzoc.htm. The UCINET function is Tools > Scaling/Decomposition $>$ Metric MDS (with the option 'adjust data to nearest Euclidian'). 
Figure 3. (Colour online) World map of clusters of legal systems.

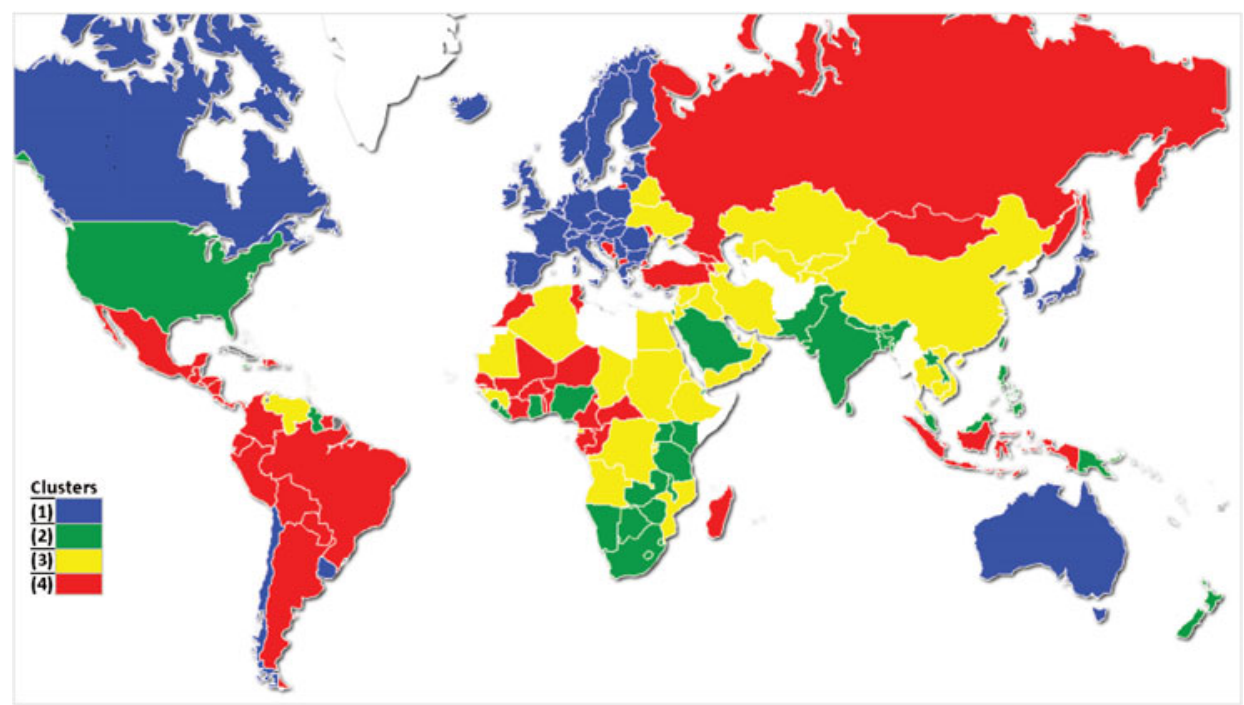

coloured and shaped according to the clusters (with lines between them added). In general, this was straight-forward, but see also the two enclaves (Ukraine and Kyrgyzstan) in the fourth cluster.

In substance, the countries that are at the borders of each cluster are particularly interesting: for example, it can be seen that New Zealand is indeed close to the other Anglophone countries, that Uruguay, South Korea and Chile are at the borders of the European cluster, and that Montenegro, Macedonia and Georgia are at the borders of the transition to the European cluster.

The main cluster divisions, and their naming, can now be explained as follows. First, the 'European Legal Culture' cluster mainly consists of European countries from any legal tradition: Germanic, French and Nordic civil law but also common law countries. Furthermore, it includes some non-European countries that have been strongly influenced by European legal systems and that perform well in institutional indicators. It can then also be seen that, within this cluster, the Anglophone and Nordic countries are close together - and a bit apart from the main group of continental countries. This result is not implausible as all of those latter countries share good institutions but without the comprehensive codes of (other) continental European countries.

The second cluster is called 'Mixed Legal Systems' since it includes countries that have at least some features of common law systems but are also mixed with civil law and/or religious legal traditions. It also includes South Africa, Sri Lanka, Israel, Botswana, Guyana, Lesotho, Namibia, Zimbabwe and the Philippines which the literature often classifies as mixed legal systems (Kim, 
Figure 4. (Colour online) Map of legal systems (with metric MDS) ${ }^{11}$.

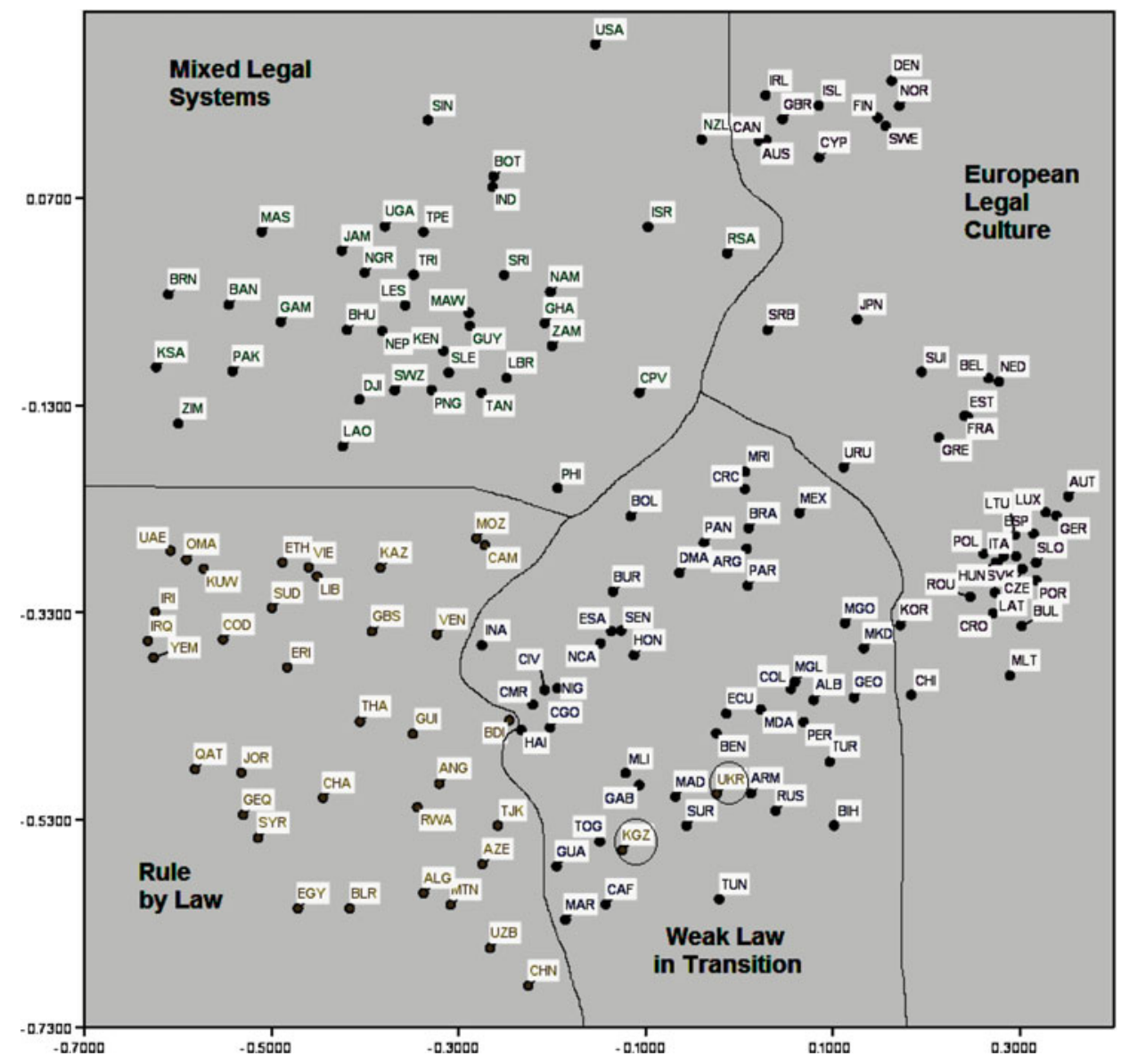

2010: 705; for other mixtures, see Siems, 2014: 85-93). The common-law nature of some countries of this cluster matches their history as former English colonies (e.g., India, Kenya), while for others this influence may be of more recent origins, possibly also through US law (e.g., the Philippines, Taiwan). It is also noteworthy that the US is at the far end of both this cluster and the chart, thus possibly confirming statements about the 'exceptionalism' of US law (e.g., Kagan, 2001).

Third, the cluster 'Rule by Law' consists of many non-democratic countries, often with a socialist background as well as some countries of Islamic law. These countries are loosely scattered over a relatively wide area of Figure 4. It can, however, be observed that the Muslim countries of the Middle East tend to be on the left-hand side of the cluster, and that the central Asian countries

11 This figure uses the IOC country codes as abbreviations, see http:/www.statoids.com/wab.html. 
Table 8. Means of variables per each of the clusters

\begin{tabular}{llllll}
\hline \hline & $\begin{array}{l}\text { (1) European } \\
\text { Variables }\end{array}$ & $\begin{array}{l}\text { (2) Mixed legal } \\
\text { legal culture }\end{array}$ & $\begin{array}{l}\text { (3) Rule } \\
\text { by law }\end{array}$ & $\begin{array}{l}\text { (4) Weak law } \\
\text { in transition }\end{array}$ & Total \\
\hline $\begin{array}{l}\text { (1) Countries of latin notariat } \\
\text { (2) Islam state religion }\end{array}$ & 0.711 & 0.000 & 0.135 & 0.977 & 0.474 \\
& & & & & \\
& 0.000 & 0.132 & 0.297 & 0.047 & 0.115 \\
(3) EU/EEA countries & $\mathbf{0 . 7 8 9}$ & 0.000 & 0.000 & 0.000 & 0.192 \\
(4) Participation in international & $\mathbf{0 . 9 5 6}$ & 0.237 & 0.225 & 0.403 & 0.455 \\
$\quad$ commercial law & & & & & \\
(5) Participation in international & 0.904 & 0.614 & 0.333 & 0.705 & 0.643 \\
courts & & & & & \\
(6) Rule of law & 0.791 & 0.431 & 0.259 & 0.330 & 0.450 \\
(7) Judicial independence & 0.360 & 0.583 & 0.324 & 0.438 & 0.427 \\
$\quad$ (according to constitution) & & & & & \\
(8) Constitutional court & 0.526 & 0.053 & 0.405 & 0.488 & 0.372 \\
(9) Civil code & 0.711 & 0.092 & 0.986 & 0.930 & 0.686 \\
(10) Democracy index & $\mathbf{0 . 7 8 4}$ & 0.491 & 0.229 & 0.474 & 0.495 \\
(11) Civil liberties infringed & 0.039 & 0.430 & 0.730 & 0.399 & 0.397 \\
(12) Business freedom & $\mathbf{0 . 7 6 9}$ & 0.571 & 0.479 & 0.523 & 0.584 \\
(13) Labour freedom & 0.541 & 0.570 & 0.499 & 0.450 & 0.513 \\
(14) Death penalty not abolished & 0.026 & 0.474 & 0.568 & 0.047 & 0.269 \\
(15) Abortion permitted & $\mathbf{0 . 8 6 1}$ & 0.538 & 0.514 & 0.492 & 0.598 \\
\hline \hline
\end{tabular}

are on the right hand side, closer to the 'transition' cluster. China is at the bottom end of this cluster, thus - similar to the US - possibly confirming research that China has a somehow unique institutional structure (see, e.g., Liebman, 2014).

The fourth cluster, 'Weak Law in Transition', has been the most difficult to name. It includes a variety of countries from Latin America, Africa, Asia and South-East Europe. Many of the countries in this cluster can be seen as countries in transition. Overall, these countries also have in common that they have decent but not perfectly working legal institutions, as will also be apparent from the discussion of the following section.

\section{Relationship between clusters and variables}

In order to gain a fuller understanding of the clusters, it is helpful to identify which variables drive the results for each of these. Table 8 reports the means for each of the clusters, highlighting both the highest values (in bold) and the lowest ones (in italics).

Table 8 shows that the countries of the first cluster have in common that they are typically (but not only) EU/EEA countries with high values in the categories international commercial law, participation in international law, rule of law, democracy, business freedom and permission of abortions. Thus, this group 
is characterised by countries with broadly liberal, secular and effective legal systems.

With respect to the mixed second cluster, the low values in the variables on Latin Notariat, constitutional court and Civil Code and the high value in the constitutional provision of judicial independence can be seen as common-law indicators. But these countries are also quite different from contemporary UK (or English) law with low or intermediate values for rule of law, civil liberties, democracy, business freedom as well as retention of the death penalty. Thus, this shows a certain tension between existing traditions and effective protection of rights.

The scores in the variables of the third cluster confirm the features of a 'rule by law': low values on rule of law, judicial independence and democracy, many civil rights infringements and a harsh criminal law (as seen by the retention of the death penalty and the ban of abortion). While almost all of those countries have Civil Codes, it is noteworthy that they do not tend to participate in the Latin Notariat, international commercial law and international courts. Overall, this leads to a cluster of countries that are furthest apart from the cluster of the European legal culture - and those are indeed the only two clusters that do not share a border in Figure 4.

In some respects, the fourth cluster is similar to the previous one, for instance, with a low score for rule of law and a high one for Civil Code. However, almost all of these countries have abolished the death penalty and score higher in terms of judicial independence, democracy and respect for civil liberties. In addition, the association with the Latin Notariat and the greater readiness to participate in international commercial law and international courts shows a willingness to improve their legal infrastructure. Thus, in the future, some of these countries may shift to the cluster of the European legal culture - as it may be assumed that some of the countries in the latter cluster (such as Uruguay, Chile, Croatia, Serbia) may have gone through this transition in recent decades.

\section{Conclusion}

This paper has explored a new dataset of 156 legal systems with tools of network and cluster analysis. Network analysis can indicate similarities between country pairs which can show how the law of one country has been influenced by two or more other countries. Moreover, even when we identify community structures such as clusters, this does not deny possible ambiguities. As this paper has shown, the clusters of 'European Legal Culture', 'Mixed Legal Systems', the 'Rule by Law' and the 'Weak Law in Transition' can be displayed in a map with countries that are close to the borders of their respective clusters, thus indicating complex sources of influence.

This analysis therefore confirms the first reason to develop taxonomies of legal systems (see 2, above), namely that, at the descriptive level, the foregoing findings 
are helpful in order to identify the main dividing lines of the legal systems of the world. Of course, this does not mean that those categories are necessarily relevant for each and every legal concept. Thus, researchers may use the taxonomy as a starting point but may then also discuss how far it does, or does not, capture any specific legal concept of interest.

Second, analytically, the network data presented here may be linked to further datasets. The current paper was based on the idea that attributes can be transformed into relations showing differences and similarities between countries. Future research can identify how these data are related to explicit data on legal relations, for example, cross-citations between courts (e.g., Gelter and Siems, 2013) or technological, social, biological and information networks (for those networks see Kolaczyk, 2009: 3-10).

Moreover, it can be scrutinised how the legal networks and clusters are correlated to historical, social, political, economic and cultural similarities and differences. For example, applying the concept of an 'affiliation network' aims to identify a shared event that indicates the presence of particular ties (see Borgatti and Halgin, 2011). It would also be interesting to establish whether there may be a causal relationship between the clusters and economic development. However, this raises the problem of law's endogeneity (see, e.g., Deakin 2015). While the 'legal origins' of the law and finance research may, to some extent, be seen as exogenous, La Porta et al. (2008: 298), now also acknowledge that using them as instrumental variables can be inappropriate and that they may actually proxy for other channels.

Third, there may be normative lessons that can be drawn from the analysis of this paper. For example, the fact that the data have led to a mainly European cluster of different legal traditions indicates that within this group EU harmonisation may be less problematic than it is sometimes assumed (Legrand, 1996). Considering the use of foreign legal models, it is conceivable that a country may have a tendency to transplant rules from neighbouring countries in the map of legal systems of Figure 4. However, it could also be the case that a country has the aim to change its position in this map: for example, adopting the view that 'getting to Denmark' equates the desire to move to the model of 'stable, peaceful, prosperous, inclusive, and honest societies' (Fukuyama, 2011: 12), the aspiration would be to get towards the top right hand corner of Figure 4.

\section{Acknowledgements}

The author wishes to thank the participants of the 10th Annual Conference of the Asian Law and Economics Association (AsLEA) in Taipei, the Inaugural conference of the World Interdisciplinary Network for Institutional Research (WINIR) in London and the 31st Annual Conference of the European Association of Law and Economics (EALE) in Aix-en-Provence, and workshops 
in London (LSE and Queen Mary University of London), specifically Chia-Shin Hsu, Boudewijn Bouckaert and William Twining, as well as two anonymous referees for helpful comments.

\section{References}

Armour, J., S. Deakin, P. Sarkar, M. Siems, and A. Singh (2009), 'Shareholder Protection and Stock Market Development: A Test of the Legal Origins Hypothesis', Journal of Empirical Legal Studies, 6: 343-380.

Bavinck, M. and G. R. Woodman (2009), 'Can There be Maps of Law?', in F. von BendaBeckmann, K. von Benda-Beckmann, , and A. Griffiths (eds.), Spatializing Law: An Anthropological Geography of Law in Society, Abingdon: Ashgate, pp. 195-218.

Berkowitz, D., K. Pistor, and J.-F. Richard (2003a), 'Economic Development, Legality, and the Transplant Effect', European Economic Review, 47: 165-195.

Berkowitz, D., K. Pistor, and J.-F. Richard (2003b), 'The Transplant Effect', American Journal of Comparative Law, 51: 163-204.

Bogdan, M. (1994), Comparative Law, Stockholm: Kluwer.

Borgatti, S. P. and D. S. Halgin (2011), 'Analyzing Affiliation Networks', in J. Scott and P. J. Carrington (eds.), The SAGE Handbook of Social Network Analysis, London: Sage, pp. 417-433.

Coe, N. M., P. F. Kelly, and H. W. C. Yeung (2010), Economic Geography, Malden, AM: Blackwell.

Constantinesco, L.-J. (1983), Rechtsvergleichung, Band III: Die Rechtsvergleichende Wissenschaft, Cologne: Carl Heymanns.

David, R. (1985), Major Legal Systems in the World Today: An Introduction to the Comparative Study of Law, 3rd edn., London: Stevens.

Deakin, S. (2015), 'The Evolution of Theory and Method of Law and Finance', in E. Ferran, N. Moloney, and J. Payne (eds.), The Oxford Handbook of Financial Regulation, Oxford: Oxford University Press, pp. 13-40.

Derrett, J. D. M. (ed.) (1968), An Introduction to Legal Systems, London: Sweet \& Maxwell.

Djankov, S., R. La Porta, F. Lopez-de-Silanes, and A. Shleifer (2008), 'The Law and Economics of Self-Dealing', Journal of Financial Economics, 88, 430-465.

Ferreres Comella, V. (2011), 'The Rise of Specialised Constitutional Courts', in T. Ginsburg and R. Dixon (eds.), Research Handbook in Comparative Constitutional Law, Cheltenham: Edward Elgar, pp. 265-277.

Ferligoj, A., P. Doreian and V. Batagelj (2011), 'Positions and Roles', in J. Scott and P. J. Carrington (eds.), The SAGE Handbook of Social Network Analysis, London: Sage, pp. 434-446.

Fukuyama, F. (2011), The Origins of Political Order, London: Profile Books.

Garoupa, N. and T. Ginsburg (2011). 'Hybrid Judicial Career Structures: Reputation v Legal Tradition', Journal of Legal Analysis, 3: 411-448.

Garoupa, N. and M. Pargendler (2014), 'A Law and Economics Perspective on Legal Families', European Journal of Legal Studies, 7: 36-60.

Gelter, M. and M. Siems (2013), 'Language, Legal Origins, and Culture before the Courts: Cross-Citations between Supreme Courts in Europe', Supreme Court Economic Review, 21: 215-269.

Glenn, H. P. (2014), Legal Traditions of the World, 5th edn., Oxford: Oxford University Press. 
Graff, M. (2008), 'Law and Finance: Common Law and Civil Law Countries Compared - An Empirical Critique', Economica, 75: 60-83.

Hall, P. A. and D. Soskice (2001), Varieties of Capitalism: The Institutional Foundations of Comparative Advantage, Oxford: Oxford University Press.

Hanneman, R. and M. Riddle (2005), 'Introduction to Social Network Methods', available at http://faculty.ucr.edu/ hanneman/nettext/ (accessed 4 January 2016).

Hertel, C. (2009), 'Legal Systems of the World - An Overview', Notarius International, 128141.

Husa, J. (2004), 'Classification of Legal Families Today. Is it Time for a Memorial Hymn?', Revue Internationale de Droit Comparé, 11-38.

Husa, J. (2012), 'Legal Families', , in J. M. Smits (ed.), Elgar Encyclopaedia of Comparative Law, 2nd edn., Cheltenham: Edward Elgar, pp. 491-504.

Inglehart, R. and C. Welzel (2010), 'Changing Mass Priorities: The Link Between Modernization and Democracy', Perspectives on Politics, 8: 554-567.

Kagan, R. A. (2001), Adversarial Legalism: The American Way of Law. Cambridge, MA: Harvard University Press.

Kaufmann, D., A. Kraay, and M. Mastruzzi (2010), 'The Worldwide Governance Indicators: Methodology and Analytical Issues', World Bank Policy Research Working Paper No. 5430, available at http://ssrn.com/abstract=1682130 (accessed 4 January 2016).

Kick, E. L., L. A. McKinney, S. McDonald, and A. Jorgenson (2011), 'A Multiple-Network Analysis of the World System of Nations, 1995-1999', in J. Scott and P. J. Carrington (eds.), The SAGE Handbook of Social Network Analysis, London: Sage, pp. 311-327.

Kim, K. (2010), 'Mixed Systems in Legal Origins Analysis', Southern California Law Review, 83: 693-728.

Klerman, D. M., P. G. Mahoney, H. Spamann, and M. I. Weinstein (2011), 'Legal Origins or Colonial History?', Journal of Legal Analysis, 3: 379-409.

Knoke, D. and S. Yang (2008), Social Network Analysis, 2nd edn, Los Angeles: Sage.

Kolaczyk, E. D. (2009), Statistical Analysis of Network Data, New York: Springer.

Kurtz, M. J. and A. Schrank (2007), 'Growth and Governance: Models, Measures, and Mechanisms', Journal of Politics, 69: 538-554.

La Porta, R., F. Lopez-de-Silanes, and A. Shleifer (2008), 'The Economic Consequences of Legal Origins', Journal of Economic Literature, 46: 285-332.

La Porta, R., F. Lopez-de-Silanes, A. Shleifer, and R. Vishny (1998), 'Law and Finance', Journal of Political Economy, 106: 1113-55.

Lalenis, K., M. De Jong, and V. Mamadouh (2002), 'Families of Nations and Institutional Transplantation', in M. De Jong, K. Lalenis, and V. Mamadouh (eds.), The Theory and Practice of Institutional Transplantation, Dordrecht: Kluwer, pp. 33-52.

Legrand, P. (1996), 'European Legal Systems Are Not Converging', The International and Comparative Law Quarterly, 45: 52-81.

Lewis, M. P., G. F. Simons, and C. D. Fennig (eds.) (2013), Ethnologue: Languages of the World, 17th edn., Dallas, Texas: SIL International.

Liebman, B. L. (2014), 'Legal Reform: China's Law-Stability Paradox', Daedalus, 143: 96109.

Lloyd, P., M. C. Mahutga, and J. de Leeuw (2009), 'Looking Back and Forging Ahead: Thirty Years of Social Network Research on the World-System', Journal of World-System Research, 15: 48-85.

Luts, L. A. (2011) 'Typologies of Modern Legal Systems of the World', in W. E. Butler, O. V. Kresin, and I.S. Shemshuchenko (eds.), Foundations of Comparative 
Law: Methods and Typologies, London: Wildy, Simmonds and Hill Publishing, pp. 36-52.

Mattei, U. (1997), 'Three Patterns of Law: Taxonomy and Change in the World's Legal Systems', American Journal of Comparative Law, 45: 5-44.

Menski, W. (2006), Comparative Law in a Global Context, 2nd edn., Cambridge: Cambridge University Press.

Mische, A. (2011), 'Relational Sociology, Culture, and Agency', in J. Scott and P. J. Carrington (eds.), The SAGE Handbook of Social Network Analysis, London: Sage, pp. 80-97.

Nielsen, L. (2011), 'Classifications of Countries Based on Their Level of Development: How it is Done and How it Could be Done', IMF Working Paper WP/11/31, available at www.imf.org/external/pubs/ft/wp/2011/wp1131.pdf (accessed 4 January 2016).

Pargendler, M. (2012), 'The Rise and Decline of Legal Families', American Journal of Comparative Law, 60: 1043-1074.

Peters, A. and H. Schwenke (2000), 'Comparative Law Beyond Post-modernism', International and Comparative Law Quarterly, 49: 800-834.

Popper, S. K. (1963), Conjectures and Refutations, London: Routledge.

Reimann, M. (2001), 'Beyond National Systems: A Comparative Law for the International Age', Tulane Law Review, 75: 1103-1120.

Reynolds, T. and A. Flores (1989), Foreign Law: Current Sources of Basic Legislation in Jurisdictions of the World, Littleton, CO: Rothman.

Siems, M. (2007), 'Legal Origins: Reconciling Law \& Finance and Comparative Law', McGill Law Journal, 52: 55-81.

Siems, M. (2008). 'Shareholder Protection Around the World ('Leximetric II')', Delaware Journal of Corporate Law, 33: 111-147.

Siems, M. (2010). 'The Web of Creditor and Shareholder Protection: A Comparative Legal Network Analysis', Arizona Journal of International and Comparative Law, 27: 747784.

Siems, M. (2014). Comparative Law, Cambridge: Cambridge University Press.

Siems, M. and S. Deakin (2010), 'Comparative Law and Finance: Past, Present and Future Research', Journal of Institutional and Theoretical Economics (JITE), 166: 120-140.

Snyder, D. and E. L. Kick (1979), 'Structural Position in the World System and Economic Growth, 1955-1970: A Multiple-Network Analysis of Transnational Interactions', American Journal of Sociology, 84: 1096-1126.

Sommerer, T., K. Holzinger, and C. Knill (2008), 'The Pair Approach: What Causes Convergence of Environmental Policies?', in K. Holzinger, C. Knill, and B. Arts (eds.), Environmental Policy Convergence in Europe, Cambridge: Cambridge University Press, pp. 144-195.

Twining, W. (1999). 'Mapping Law', Northern Ireland Legal Quarterly, 50: 12-49.

Twining, W. (2000), Globalisation and Legal Theory, London: Butterworths.

Vanderlinden, J. (1995), Comparer les droit, Diegem: E. Story-Scientia.

Varga, C. (2010), 'Taxonomy of Law and Legal Mapping, Patterns and Limits of the Classification of Legal Systems', Acta Juridica Hungarica, 51: 253-272.

Voigt, S. 2013. 'How (Not) to Measure Institutions', Journal of Institutional Economics, 9: $1-26$.

Zweigert, K. and H. Kötz (1998), An Introduction to Comparative Law, 3rd edn., Oxford: Clarendon. 